\title{
Clean Coal Technologies for Electricity and Synthetic Liquid Fuel Production for Distributed Generation
}

\author{
Elina TYURINA ${ }^{1}$, Aleksandr MEDNIKOV ${ }^{2 *}$, Pavel ZHARKOV ${ }^{3}$ \\ ${ }^{1-3}$ Melentiev Energy Systems Institute SB RAS, 130, Lermontov str., Irkutsk, Russia
}

\begin{abstract}
The paper presents energy technology installations for combined production of methanol and electricity for distributed generation. The technical and economic study is based on mathematical modeling using a system of computer-aided construction of programs and optimization with the models. The results of the effect of fuel composition on methanol and electricity production are presented. The competitiveness of the obtained methanol is assessed. The studies were carried out for various electricity and coal costs. The thermal efficiency of such installations is more than $60 \%$. At present methanol produced at energy technology installations is competitive with expensive diesel fuel delivered from other areas.
\end{abstract}

Keywords - Coal; co-production; methanol; modeling; synthetic fuel

\begin{tabular}{|lll|}
\hline \multicolumn{2}{|l|}{ Nomenclature } & \\
$B_{\mathrm{f}}$ & Annual coal consumption & $\mathrm{kg}$ per year \\
$C_{\mathrm{el}}$ & Electricity cost & $\mathrm{USD} / \mathrm{kWh}$ \\
$C_{\mathrm{f}}$ & Coal cost & $\mathrm{USD} / \mathrm{t}$ \\
$C_{\mathrm{meth}}$ & Methanol cost & $\mathrm{USD} / \mathrm{tce}$ \\
$d k, d w$ & Consumption of steam gasification agent & $\mathrm{kg} / \mathrm{s}$ \\
ETIs & Energy technology installations & - \\
$G$ & Vector of inequality constraints & - \\
$G C V$ & Gross Calorific Value & $\mathrm{MJ} / \mathrm{kg}$ \\
$H$ & Vector of equality constraints & - \\
$I R R_{z}$ & Set internal rate of return & $\%$ \\
$K_{\mathrm{I}}$ & Investments in modular power plant & $\mathrm{USD}$ \\
$P_{\mathrm{el}}$ & Annual electricity production & $\mathrm{kWh}$ per year \\
$P_{\mathrm{meth}}$ & Annual methanol production & $\mathrm{kg}$ per year \\
$\mathrm{QLF}$ & Qualified liquid fuels & - \\
$x$ & Vector of independent optimized parameters & - \\
$x_{\min }, x_{\text {max }}$ & Vectors of the boundary values of the optimized parameters & - \\
$y$ & Vector of dependent calculated parameters & - \\
\hline
\end{tabular}

* Corresponding author.

E-mail address: mednikov@isem.irk.ru

(C)2020 Elina Tyurina, Aleksandr Mednikov, Pavel Zharkov.

This is an open access article licensed under the Creative Commons Attribution License (http://creativecommons.org/ licenses/by/4.0), in the manner agreed with Sciendo. 


\section{INTRODUCTION}

The energy strategy of Russia for the period until 2030 considers the small-scale distributed energy to be one of the key areas of the energy sector development. A special purpose of small-scale energy is to ensure reliable energy supply to the areas remote from the network infrastructure [1], [2]. In the absence of technical ability to connect the consumer to a centralized energy supply system, the consumer can build an individual source of energy supply [3].

In this context, one of the promising solutions is the construction of energy technology installations (ETIs) for the co-production of electricity and synthetic qualified liquid fuels (QLF) near coal mining enterprises in remote regions of Siberia and the Far East. This will provide energy to remote consumers, significantly expand the market for coal products in the eastern regions, and improve the environmental situation.

In this paper, we will consider one of the promising ways of processing coal into electricity and QLF. It consists in gasification with the production of syngas [4] enriched with hydrogen and carbon monoxide; synthesis of qualified liquid fuels and generation of electricity by utilizing the heat of gasification and QLF synthesis and combustion of the purge gas produced during the synthesis. Methanol that is an environmentally friendly energy carrier is considered as a qualified liquid fuel. Coal processing into liquid fuel considerably reduces expenses on transportation of a unit of chemical energy of the fuel [5].

An important feature of such combined processes is their environmental friendliness, which is due to high requirements for the syngas cleanness in the synthesis catalysts. In addition, these processes are characterized by low $\mathrm{NO}_{\mathrm{x}}$ emissions associated with small volumes of purge gases burned in the combustion chamber of the gas turbine of the power generation unit. It is also possible to recycle $\mathrm{CO}_{2}$ owing to the low flue gas volumes of the power generation unit compared to traditional power plants [6]-[8]. The energy efficiency and economic feasibility of such a complex technology is much higher than that of individual productions [8]-[10].

The main ways to study such technologies are mathematical modeling and techno-economic optimization of their schemes and parameters.

The world scientific and industrial communities pay great attention to researches into energy technology productions.

A detailed plant-wide modeling of coal-to-liquids process with different entrained flow gasifiers is described in [11]. Three types of coal-to-liquids process with different entrained flow gasifiers (GSP, Shell and Texaco) are studied using thermodynamic, techno-economic and $\mathrm{CO}_{2}$ emissions analysis. In this paper, the impact of gasifiers selection on implementation of the coal-to-liquids process is evaluated.

Sh. Yang et al. [12] provide suggestions for the cleaner production and sustainable development of coal-to-liquids technology. Lurgi, Texaco, and Shell coal-to-liquids processes are simulated, and a techno-economic analysis to investigate their implementation using simulation-based results is presented.

H. Zhou et al. [13] perform a techno-economic analysis of plants based on coal and shale for diesel and gasoline production. They suggest methods for improving energy efficiency and economic performance of production processes.

L. Lv et al. [14] conduct a detailed investigation into co-production of methanol and electricity based on coal/methane with a two-level adjustment system, and the potential feasibility of the system are verified by the thermodynamic calculations. 
In [15] a techno-economic analysis of the methanol and electricity poly-generation system based on coal partial gasification using Aspen Plus is presented. The effects of methanol synthesis temperature and cyclic gas reflux ratio on the system implementation are studied. The detailed economic data are obtained. The poly-generation system is compared with the integrated gasification combined cycle system.

The analysis shows that studies of technologies for the production of electric, thermal energy and QLF are mainly based on the thermodynamic analysis of efficiency. For complex technical systems as a power plant for combined production of liquid fuel and electricity, the study is carried out on the basis of variant calculations. Optimization studies of complex combined systems based on detailed models of energy and technological elements, considering the nonlinearity of the processes occurring in them, are not carried out. At the same time, without such an analysis, it is impossible to obtain optimal technical solutions and sufficiently objective economic indicators to determine competitive conditions of the technologies studied. Therefore, the solution to the above problems is the subject of this work.

The aim of the work is mathematical modelling and determination of optimal schemes and parameters of ETIs for distributed generation based on coals from Russia's eastern regions.

\section{Mathematical Modelling OF ETI}

The work considers the technological scheme of ETI, conventionally presented in the form of 3 units: coal gasification (I), methyl alcohol synthesis (II), electricity production (III) (Fig. 1) [16].

The unit I includes a fluidized-bed gasifier, a syngas cooling system and a syngas purification system. The steam received in this unit enters a steam turbine.

The synthesis of methanol and the generation of steam are carried out in unit II. It has several sequential synthesis stages with a different number of reactors operating in parallel.

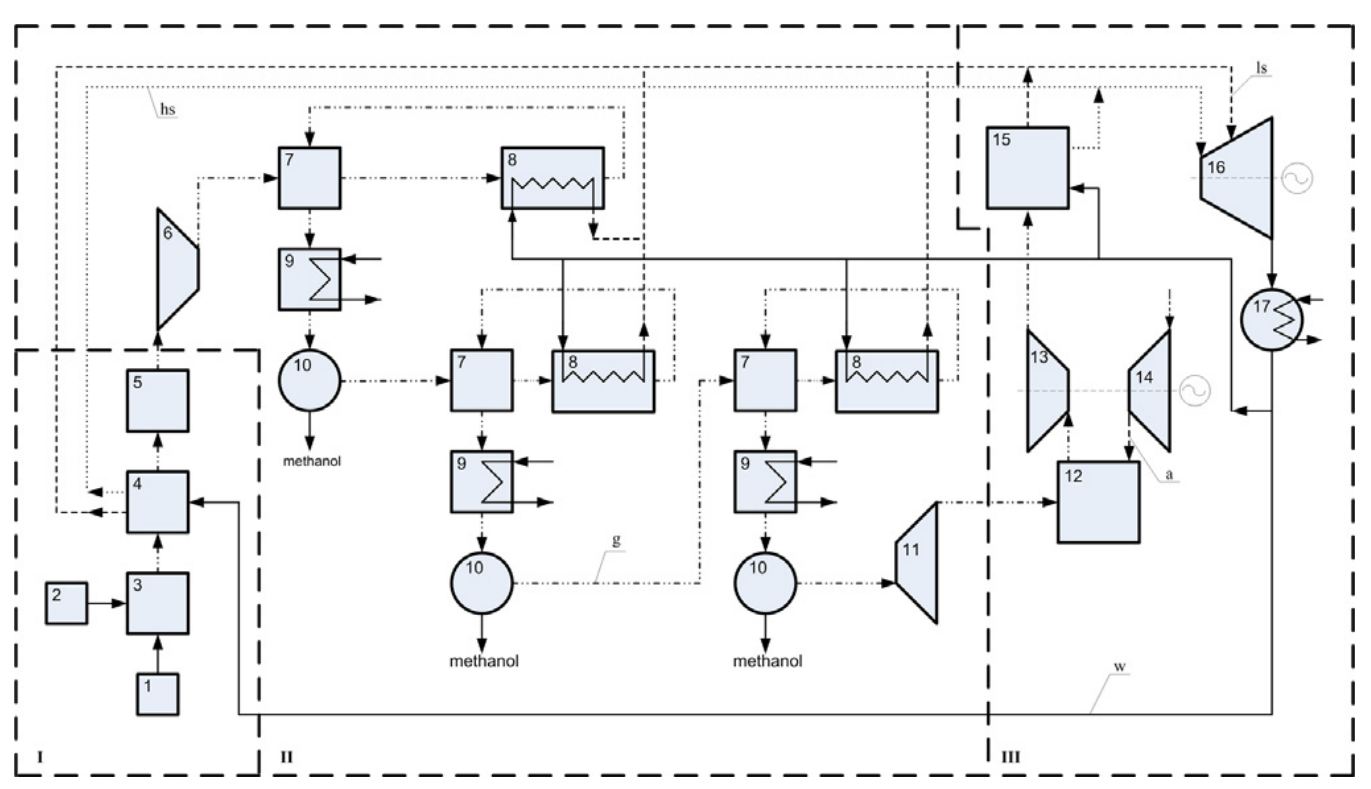

Fig. 1. Flow diagram of ETI. 
Notes: g - gas, w - feed water, ls - low-pressure steam, hs - high-pressure steam, a - air; I - gasification unit, II unit of methyl alcohol synthesis, III - energy unit; 1 - the system of fuel preparation and supply, 2 - system of air decomposition, 3 - gasifier, 4 - the system for syngas cooling, 5 - the system for syngas cleaning, 6 - compressor of syngas, 7 - regenerative gas-gas heat exchangers, 8 - reactors for the methyl alcohol synthesis, 9 - condensers, 10 - separators of raw methanol, 11 - expansion turbine, 12 - chamber for the purge gas combustion, 13 - gas turbine, 14 - air compressor, 15 - waste-heat boiler, 16 - steam turbine, 17 - condenser of steam turbine.

Combustion of the unreacted syngas from the unit II, combustion products cooling and electricity production by the gas turbine and steam turbine take place in the unit III.

The considered ETI is a complex technical system comprising a large number of different elements with diverse technological ties. Modelling such an installation is a difficult task. The method of decomposition is one of the most efficient ways to overcome it. It consists in dividing the flow diagram of the installation into separate parts with more simple ties. Mathematical models for each part are developed. Then the models are correlated with one another.

All models were built with using a software and computer complex - an automated programs construction system (APCS), which was developed at the Melentiev Energy Systems Institute SB RAS [17], [18]. This system allows the automatic construction of programs for calculating the complex technical system on FORTRAN using the data on the elemental composition of the flow diagram and ties between elements [16].

The mathematical model of unit I include simultaneous equations of reaction chambers and the space above the fluidized bed of the gasifier, radiation and convective heat exchangers, in which gasification products are water-cooled or steam-cooled, syngas purification systems, etc. The composition of the gasification products and the temperature of the process are determined by solving the simultaneous equations of the law of active masses for reactions of $\mathrm{CO}$ and $\mathrm{CH}_{4}$ conversion by steam, the equations of thermal and material balance for individual chemical elements. The heat balance equations consider heat transfer from the fluidized bed to the radiation heat exchangers. The mathematical models of heat exchangers are intended for determining the required area of heating surface and other design characteristics. They allow the thermal, hydraulic and aerodynamic calculations to be performed, and the temperature of pipe metal and the mechanical stresses acting in the metal to be determined. The mathematical models of the systems for cleaning the gasification products (cyclones, scrubbers, absorbers) enable to determine efficiency of harmful components capture, heat losses, aerodynamic resistance and design characteristics.

The mathematical model of unit II combines the mathematical descriptions of syngas compressor, methanol synthesis catalytic reactor, regenerative gas-gas heat exchangers, and liquid methanol condenser and separator. The required mechanical power and the temperature of the syngas at the outlet are determined in the compressor model. A cylindrical direct-flow reactor for methanol synthesis, consisting of several catalyst layers with built-in convective heat exchangers is considered. Water cools syngas in these heat exchangers, low pressure steam is generated. It is sent to the power unit [16].

The mathematical models of the built-in and regenerative gas-gas exchangers include equations of heat balance, heat transfer, and equations of hydraulic and aerodynamic resistances. Along with these dependencies, a model of the condenser includes equations determining the distribution of $\mathrm{CH}_{3} \mathrm{OH}$ and $\mathrm{H}_{2} \mathrm{O}$ between liquid and gaseous phases. The heat balance equation considers heat release during $\mathrm{CH}_{3} \mathrm{OH}$ and $\mathrm{H}_{2} \mathrm{O}$ condensation [16].

The mathematical model of unit III includes a mathematical description of the energy elements: air compressor, steam turbine, gas turbine, combustion chamber of the gas turbine and waste heat boiler [16]. 
The models of the turbo-units are used for define changes of the working medium parameters during expansion or compression and generated or consumed power. The model of the gas turbine takes into account reduction of the thermal efficiency due to cooling by air. The mathematical model of the compartments of a steam turbine takes into account a decrease in energy efficiency when working with wet steam [16].

The mathematical model of the combustion chamber includes equations of heat and material balances for individual chemical elements. It is intended to determine a mix of combustion products and the required air consumption at an established gas temperature at the combustion chamber outlet [16].

The mathematical models of the heat exchangers of the waste-heat boiler comprise equations similar to heat exchangers of the gasification unit.

The ETI model contains more than 2000 variables, several hundreds of transcendental and algebraic equations. A set of equations describing the whole flow diagram of the installation is solved using the Seidel method [19], [20].

The mathematical models ETI are developed to calculate the design of elements: heating surfaces and metal mass of heat exchangers; catalyst volume in reactors; drive power of pumps and compressors, gas and steam turbines; thermodynamic and flow rates parameters of the flows of syngas, products of combustion, water and steam at various points in the technological scheme of ETI. On this basis, the main technical and economic indicators of the installation are determined: the volume of methanol and electricity production (for a given coal consumption), the energy and economic efficiency of the installation, the mass of the catalyst, the surface area of the heat exchangers, capital investments, operating costs, etc. [16].

It is impossible experimentally to verify mathematical models for the described promising ETIs. Under these conditions, it is necessary to prove the validity of the mathematical descriptions of individual physicochemical processes occurring in the components of the installations, and the accuracy of solving systems of equations describing these processes. The simulation validity of considered installations is determined by the following factors.

The gasification process of coal in steam-oxygen atmosphere, which occurs at a temperature of $1173 \mathrm{~K}$, is described with high accuracy by the laws of equilibrium thermodynamics [16], [19].

The model of methanol synthesis reactors is based on a system of differential equations describing the processes of catalytic synthesis including the rate constants for the formation of methanol and $\mathrm{CO}$ experimentally obtained at existing plants [21].

Mathematical models of the main processes occurring in energy elements and systems (steam and gas turbines, compressors, heat exchangers, combustion chambers, etc.) have been tested and are widely used in the power system [22].

Regarding the solution of algebraic and transcendental equations system describing the established conditions for the operation of ETI. A set of equations describing the whole flow diagram of the installation is solved using the Seidel method. In this case, we set high accuracy $\left(10^{-3}\right)$ for the relative error of the calculated values. These circumstances provide acceptable accuracy in the representation of mathematical models of individual elements and ETI as a whole.

A more detailed description of the methodological approaches used for the research, mathematical models of energy, chemical and technological elements of the ETI is given in previously completed papers [16]-[18]. 


\section{STUDY OF ETI}

The goal of the study carried out using the mathematical model of ETI is to determine optimum parameters of the installation and change of its economic indices depending on the external conditions.

This study is necessary to assess prospects for applying this method of coal processing for energy supply to remote regions of Russia.

An original methodology, a software and a computer complex to optimize schemes and parameters of complex thermal power and energy technology installations of various types were created at ESI SB RAS. The nonlinear programming problems were solved by the efficient "with memory" method that is based on a combination of the well-known methods of "immersion" and "feasible directions" [23]. The study was conducted on this basis, making it possible to find the best solutions in terms of both energy and economic efficiency.

The schemes and parameters of ETI were optimized for four coal deposits of Russia's eastern regions. The composition of coals per working mass is given in Table 1.

TABLE 1. COAL COMPOSITION OF VARIOUS DEPOSITS, \%

\begin{tabular}{lllllllll}
\hline Coal & C & H & S & O & N & W & A & $\begin{array}{l}\text { GCV } \\
\text { MJ/kg }\end{array}$ \\
\hline Urgalsk deposit & 46.7 & 3.3 & 0.34 & 7.7 & 0.76 & 10.2 & 31 & 18.16 \\
Dolinsk deposit & 44.5 & 3.4 & 0.3 & 12.5 & 1 & 13.1 & 25.2 & 17.76 \\
Solntsevsk deposit & 43 & 3.4 & 0.24 & 12.6 & 0.66 & 22.1 & 18 & 16.25 \\
Rakovsk deposit & 27 & 2.2 & 0.1 & 10 & 0.4 & 43 & 17.3 & 9.83 \\
\hline
\end{tabular}

Analysis of the flow diagram of ETI shows that the ratio between the methanol and electricity production most strongly affects technical and economic indicators of ETI. At a fixed coal gasification temperature, the steam consumption for blowing into gasifiers, which determines the syngas composition, and the number of reactors connected in parallel at the stages of the synthesis unit, which determines the degree of syngas conversion into methanol, are independent parameters determining the specified ratio. Therefore, the paper considers the ETI variants with different values of these parameters.

The mathematical statement of the optimization problem is given as Eqs (1)-(5):

$$
\underset{\mathrm{dw}, \mathrm{dk}, \mathrm{st}}{\min } C_{\text {meth }}\left(x, y, d w, d k, s t, B_{\mathrm{f}}, K_{\mathrm{I}}, P_{\mathrm{meth}}, P_{\mathrm{el}}, C_{\mathrm{f}}, C_{\mathrm{el}}, I R R_{z}\right)
$$

subject to

$$
\begin{aligned}
& H(x, y)=0, \\
& G(x, y) \geq 0, \\
& x_{\min } \leq x \leq x_{\max }, \\
& I R R=I R R_{z},
\end{aligned}
$$

where

$x$

vector of independent optimized parameters;

$y$

vector of dependent calculated parameters; 


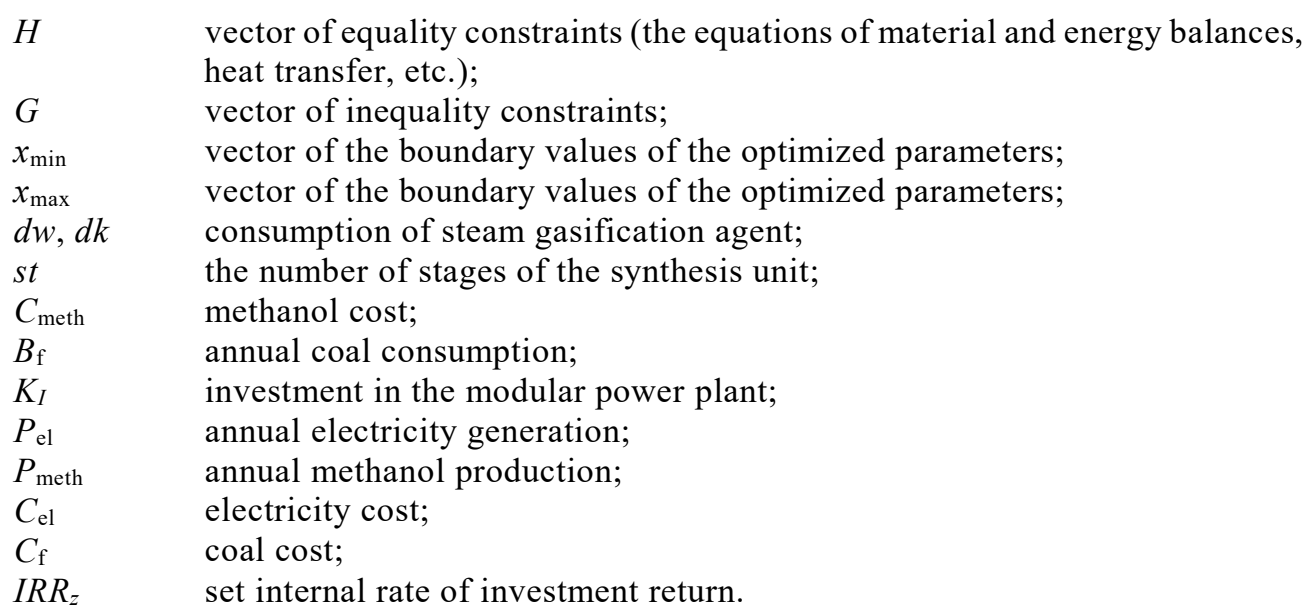

The thermodynamic parameters (enthalpy, pressure, temperature, speed, etc. of working bodies and heat carriers), flow rates and design parameters are assigned as independent optimized parameters. The system of constraints contains conditions for non-negativity of the end temperature differences in heat exchangers, pressure differences along the flow paths of steam and gas turbines, observance of the design temperature and the mechanical stress of the heat exchanger pipes, the minimum and maximum gasification temperature, etc.

The initial technical and economic information was assumed based on the previous studies that were conducted at ESI SB RAS and focused on the technologies for converting solid fuel into synthetic liquid and gaseous fuels, and on the analysis of the cost estimates of methanol and power co-production. The rise in the cost of construction and installation works, the cost of coal and electricity for the conditions of the regions under consideration was taken into account [16], [24]-[28].

Table 2 shows the optimal syngas composition, and Fig. 2 shows the optimal number of synthesis stages for each ETI variant.

TABLE 2. SyNTHESIS GAS COMPOSITION

\begin{tabular}{llccccc}
\hline Coal & \multicolumn{3}{l}{$\begin{array}{l}\text { Consumption of } \\
\text { gasification agent, } \\
\mathbf{k g} / \mathbf{s}\end{array}$} & \multicolumn{5}{c}{ Syngas composition, $\mathbf{k g} / \mathbf{s}(\mathbf{k m o l} / \mathbf{s})$} & \\
& $\mathbf{H}_{\mathbf{2}} \mathbf{O}$ & $\mathbf{O}_{\mathbf{2}}$ & $\mathbf{C O}_{\mathbf{2}}$ & $\mathbf{N}_{\mathbf{2}}$ & $\mathbf{C O}$ & $\mathbf{H}_{\mathbf{2}}$ \\
\hline Urgalsk deposit & 0.7 & 0.41 & $0.691(0.0157)$ & $0.039(0.0014)$ & $3.272(0.1169)$ & $0.395(0.1975)$ \\
Dolinsk deposit & 0.5 & 0.34 & $0.6854(0.0156)$ & $0.051(0.0018)$ & $3.44(0.123)$ & $0.327(0.1634)$ \\
Solntsevsk deposit & 0.5 & 0.39 & $0.634(0.0144)$ & $0.0338(0.0012)$ & $3.027(0.1081)$ & $0.32(0.1599)$ \\
Rakovsk deposit & 0.2 & 0.27 & $0.367(0.0083)$ & $0.02(0.0007)$ & $1.517(0.0542)$ & $0.205(0.1023)$ \\
\hline
\end{tabular}




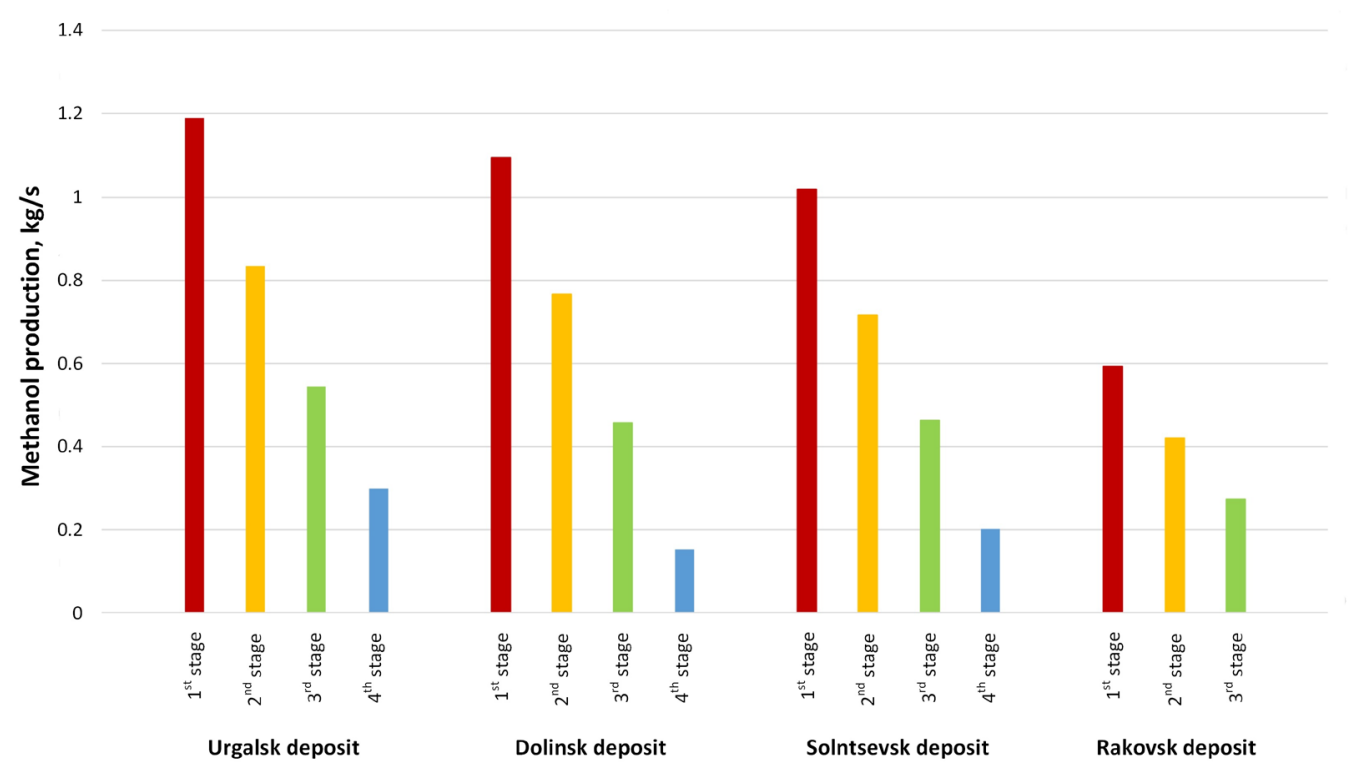

Fig. 2. The optimal number of synthesis stages.

It can be seen that the use of new direct-flow reactors in the methanol synthesis unit provides the possibility of using syngas with a lower $\mathrm{H}_{2} / \mathrm{CO}$ ratio stoichiometrically necessary (Table 2). Such composition allows reduction in energy losses and all the excessive $\mathrm{CO}$ is burnt in the energy unit. For this reason, ETI does not require an expensive unit of CO conversion. It should be noted that the specific output of synthesis reactors sharply increases (approximately twofold) due to blowout of a large amount of gas from the synthesis unit (much larger than in the technology installations for methanol synthesis).

Also, the variants differ in consumption of the gasifying agent to maintain the set gasification temperature $(1173 \mathrm{~K})$.

It can be seen that ETI based on the coal of the Rakovsk deposit has three stages of synthesis, while the other variants are represented by four stages. This is due to the fact that the syngas obtained from the "poor" coal of the Rakovsk deposit has the smallest $\mathrm{H}_{2} / \mathrm{CO}$ ratio and accordingly, the lowest methanol production.

The main techno-economic indices of the variants are given in Table 3.

Fig. 3 shows the annual methanol and electricity co-production for each optimal ETI variant.

TABLE 3. OPTIMAL TECHNO-ECONOMIC INDICES OF THE VARIANTS

\begin{tabular}{lllll}
\hline Index, unit & $\begin{array}{l}\text { Urgalsk } \\
\text { deposit }\end{array}$ & $\begin{array}{l}\text { Dolinsk } \\
\text { deposit }\end{array}$ & $\begin{array}{l}\text { Solntsevsk } \\
\text { deposit }\end{array}$ & $\begin{array}{l}\text { Rakovsk } \\
\text { deposit }\end{array}$ \\
\hline $\begin{array}{l}\text { Annual catalyst consumption, thousand t per } \\
\text { year }\end{array}$ & 204.12 & 227.28 & 197.98 & 83.62 \\
Annual coal equivalent consumption, tce & 81780.49 & 79974.34 & 73195.40 & 44282.06 \\
Annual electricity production, thousand kWh & 28436.9 & 42335.8 & 29844.7 & 24211.5 \\
$\begin{array}{l}\text { Capacity of air compressor, kW } \\
\text { Capacity of oxygen compressor, kW }\end{array}$ & 3280.76 & 4301.89 & 3162.97 & 2417.22 \\
\hline
\end{tabular}




\begin{tabular}{lllll}
\hline Capacity of syngas compressor, $\mathrm{kW}$ & 1426.97 & 1307.94 & 1221.23 & 713.04 \\
Capacity of gas turbine, $\mathrm{kW}$ & 2739.77 & 3401.20 & 2642.72 & 2079.48 \\
Capacity of exhaust-gas driven turbine, $\mathrm{kW}$ & 186.27 & 217.65 & 175.95 & 134.56 \\
Capacity of steam turbine, $\mathrm{kW}$ & 7031.83 & 7667.67 & 6966.82 & 5449.08 \\
Useful capacity of ETI, kW & 4062.42 & 6047.97 & 4263.53 & 3458.79 \\
Total auxiliary power supply, kW & 5895.45 & 5238.55 & 5521.96 & 4204.33 \\
Investments in ETI, USD thousand & 28864.44 & 26650.78 & 24771.06 & 14098.39 \\
Annual methanol production, thousand t per & 52.04 & 44.83 & 43.57 & 23.35 \\
year & 54.59 & 64.76 & 53.45 & 57.28 \\
Coal cost, USD/tce & 395.89 & 428.22 & 406.28 & 450.32 \\
Methanol price, USD/tce & 0.07 & 0.065 & 0.065 & 0.05 \\
Electricity price, USD/kWh & 71 & 66 & 67 & 62 \\
Thermal efficiency, \% & & & & \\
\hline
\end{tabular}

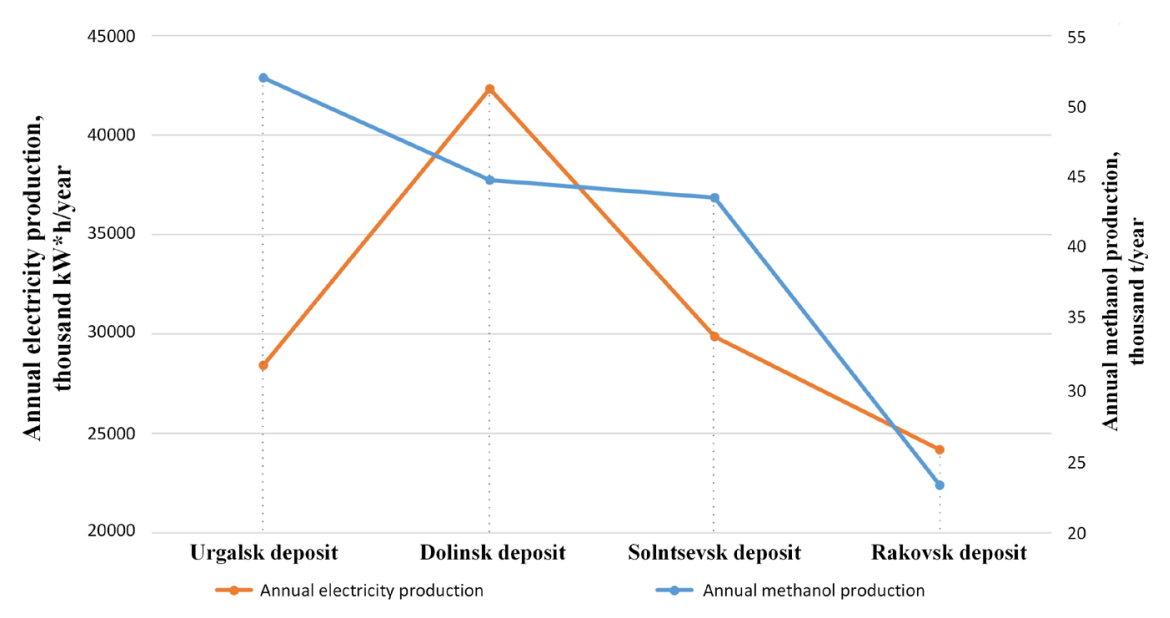

Fig. 3. Annual production of methanol and electricity for each optimal ETI variant.

ETI for the methanol production has sufficiently high thermal efficiency (about 71-62\%) as compared to the technology installation for methanol production from coal $(55 \%)$.

For a given production profitability (IRR equal to $24 \%$ ), the most effective variant from both the energy (thermal efficiency is $71 \%$ ) and economic (methanol price $395.89 \mathrm{USD} /$ tce) viewpoints is the ETI variant on the Urgalsk coal. This coal is the most high-calorific one, and the composition of the syngas based on it has the highest $\mathrm{H}_{2} / \mathrm{CO}$ ratios. The ETI variant on the poor coal of the Rakovsk deposit has the lowest efficiency (thermal efficiency is $62 \%$, methanol cost is $450.32 \mathrm{USD} /$ tce). Thus, the cost of methanol produced in the optimal ETI variants on different coals varies in the indicated range by $12 \%$.

Fig. 4 shows sensitivity of the ETI variants to changes in external conditions (electricity and coal cost). 


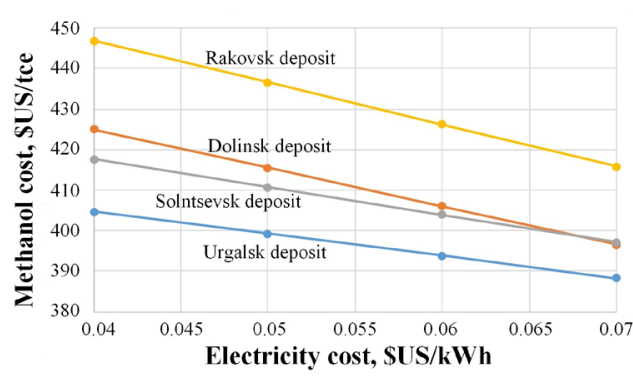

a) Fuel cost $50 \$ U S /$ tce

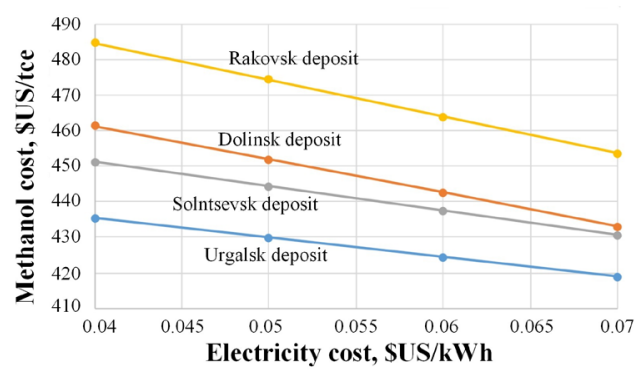

c) Fuel cost 70 \$US/tce

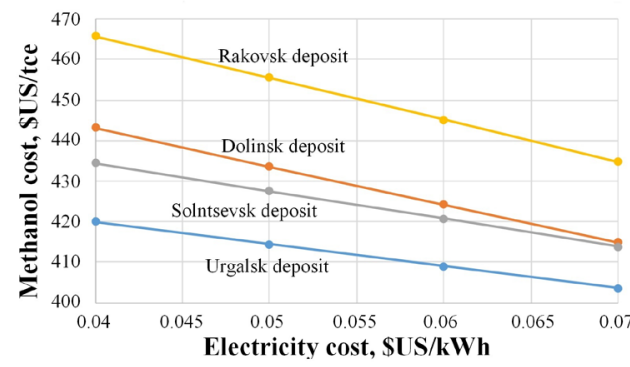

b) Fuel cost 60 \$US/tce

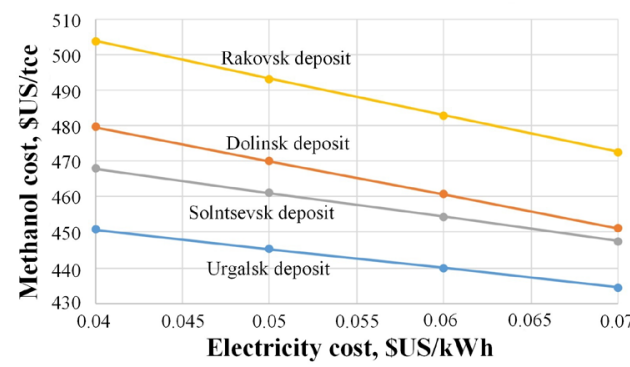

d) Fuel cost $80 \$ U S /$ tce

Fig. 4. Dependences of the methanol cost on the electricity cost at the set coal cost.

Fig. 4 shows that the cost of methanol produced at ETI varies in the range of 388$504 \mathrm{USD} / \mathrm{tce}$. Analysis of the diesel fuel cost in the regions under consideration shows that the range of its change is 595-826 USD/tce [24]-[28]. Thus, it is obvious that at present methanol produced at ETI can compete with an expensive delivered diesel fuel. In the future, this trend may improve.

Methanol Market Services Asia (MMSA) has provided its most recent historic methanol market assessment of key global pricing (Fig. 5).

This chart compares global methanol pricing in key regional markets (United States Gulf Coast, Rotterdam, Coastal China) on a spot and contract (posting before discounts) basis. The diagram shows that the price of methanol produced at ETI has a competitive range with methanol for the chemical industry.

\section{Conclusion}

The mathematical models of ETIs on coals of various deposits of Russia's eastern regions were developed. They are efficient in terms of the adequacy of representing the processes under study. The technical and economic optimization of the schemes and parameters of the installations was carried out using these models. The optimal parameters of the ETI variants were obtained. The competitiveness conditions of the studied installations were estimated. The main conclusions of the study are the following. 


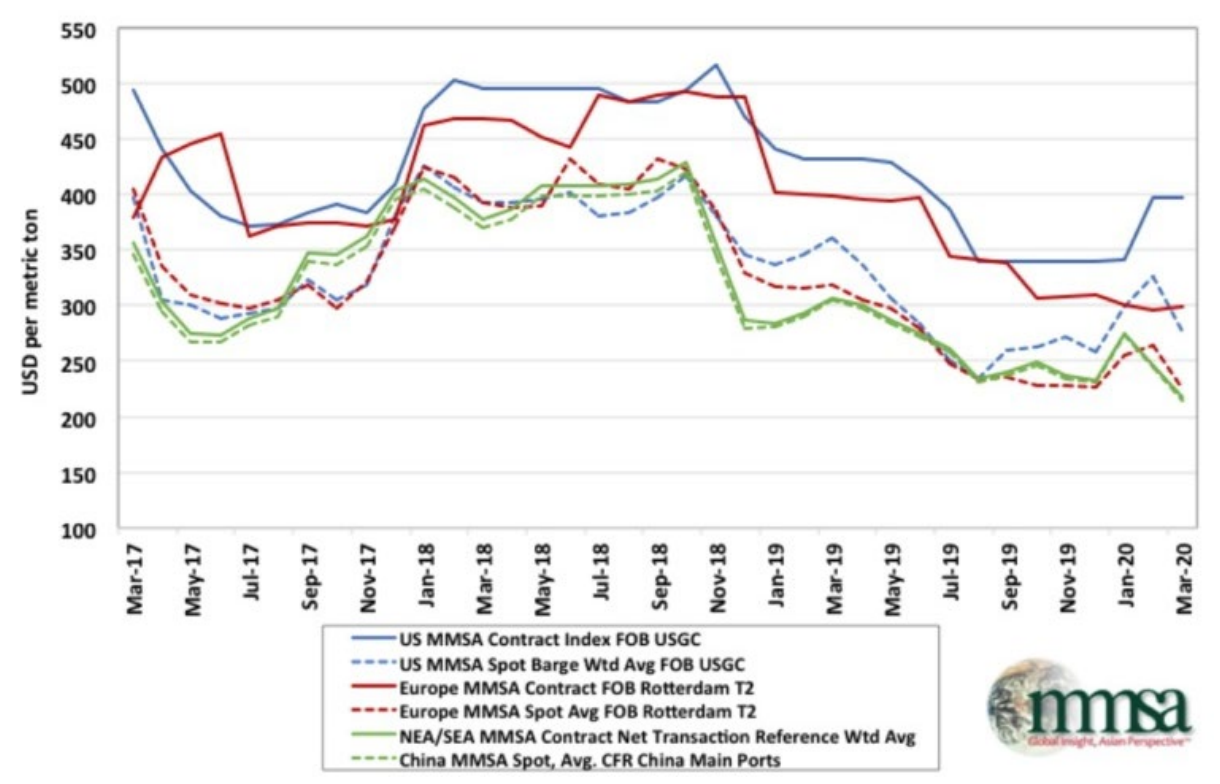

Fig. 5 Global methanol pricing [29].

Qualitative characteristics of the initial fuel have a significant impact on production efficiency. The cost of methanol produced in the optimal ETI variants on coals of various compositions varies within $12 \%$.

ETI for methanol production has sufficiently high thermal efficiency (about 71-62\%) as compared to the technology installation for methanol production from coal $(55 \%)$.

The use of direct-flow methanol synthesis reactors with intermediate cooling of the syngas between the catalyst layers allows the syngas to be used for synthesis with a lower (compared to stoichiometric) $\mathrm{H}_{2} / \mathrm{CO}$ ratio. This ensures the absence of an expensive $\mathrm{CO}$ conversion system in the synthesis unit. Thus, co-production of methanol and electricity raises thermal efficiency and reduces specific capital investment in the installation.

Sensitivity of the ETI variants to changes in external conditions (electricity and coal costs) has been investigated. Based on the analysis of the diesel fuel cost in Russia's eastern regions, it is concluded that even at present methanol produced at ETI is competitive with expensive delivered diesel fuel. Introduction of such systems is economically feasible in the near future.

It has also been shown that the price of methanol produced at ETIs has the competitive price with methanol for the chemical industry.

Thus, ETIs for methanol and electricity production based on coal presented above have competitive conditions. Further practical implementation requires pre-design studies aimed at improving synthesis catalysts, parameters of a gas turbine, gasifier, etc. In addition, it should be noted that the implementation of such costly projects requires investment support from both the state and large industrialists.

\section{ACKNOWLEDGEMENT}

The research was funded by the Russian Science Foundation, Project No. 16-19-10174. 


\section{REFERENCES}

[1] Belkin A. P., Dubova A. V. Energy efficiency. An example worthy of attention. Energetik 2016:4:13-17. (In Russian).

[2] Energy strategy of Russia for the period until 2030. [Online]. [Accessed 27.02.2020]. Available: http://minenergo.gov.ru/node/1026. (In Russian).

[3] Stennikov V., Mednikova E., Postnikov I., Penkovskii A. Optimization of the Effective Heat Supply Radius for the District Heating Systems. Environmental and Climate Technologies 2019:23(2):207-221. https://doi.org/10.2478/rtuect-2019-0064

[4] Klavins M., Bisters V., Burlakovs J. Small Scale Gasification Application and Perspectives in Circular Economy. Environmental and Climate Technologies 2018:22(1):42-54. https://doi.org/10.2478/rtuect-2018-0003

[5] Gulum M., Bilgin A. An Experimental Optimization Research of Methyl and Ethyl Esters Production from Safflower Oil. Environmental and Climate Technologies 2018:22(1):132-148. https://doi.org/10.2478/rtuect-2018-0009

[6] Miller B. G. Clean Coal Engineering Technology. 2nd Edition. Butterworth-Heinemann, 2017.

[7] Bell D. A., Towler B. F., Fan M. Gasification Fundamentals. Coal Gasification and Its Applications 2011:35-71. https://doi.org/10.1016/B978-0-8155-2049-8.10003-8

[8] Basile A., Dalena F. Methanol: Science and Engineering. 1st Edition. Elsevier, 2017.

[9] Higman C. GSTC syngas database: 2017. [Online]. [Accessed 27.02.2020]. Available: http://worldctx.com/wpcontent/uploads/HigmanGSTC2017.pdf

[10] Liu G., Larson E. D. Gasoline from Coal via DME with Electricity Co-production and $\mathrm{CO}_{2}$ Capture. Energy Procedia 2014:63:7367-7378. https://doi.org/10.1016/j.egypro.2014.11.773

[11] Qin Sh., Chang Sh., Yao Q. Modeling, thermodynamic and techno-economic analysis of coal-to-liquids process with different entrained flow coal gasifiers. Applied Energy 2018:229:413-32. https://doi.org/10.1016/j.apenergy.2018.07.030

[12] Yang Sh., Xiao Zh., Deng Ch., Liu Zh., Zhou H., Ren J., Zhou T. Techno-economic analysis of coal-to-liquid processes with different gasifier alternatives. Journal of Cleaner Production 2020:253:120006. https://doi.org/10.1016/i.jclepro.2020.120006

[13] Zhou H., Yang S., Xiao H., Yang Q., Qian Y., Gao L. Modeling and techno-economic analysis of shale-to-liquid and coal-to-liquid fuels processes. Energy 2016:109:201-210. https://doi.org/10.1016/j.energy.2016.04.108

[14] Lv L., Zhu L., Li H., Li B. Methanol-power production using coal and methane as materials integrated with a two-level adjustment system. Journal of the Taiwan Institute of Chemical Engineers 2019:97:346-355. https://doi.org/10.1016/j.jtice.2019.02.008

[15] Ye Ch., Wang Q., Zheng Y., Li G., Zhang Z., Luo Z. Techno-economic analysis of methanol and electricity polygeneration system based on coal partial gasification. Energy 2019:185:624-632. https://doi.org/10.1016/j.energy.2019.06.175

[16] Kler A. M., Tyurina E. A., Mednikov A. S. A plant for methanol and electricity production: Technical-economic analysis. Energy 2018:165(B):890-899. https://doi.org/10.1016/j.energy.2018.09.179

[17] Kler A. M., Tyurina E. A. (Ed.). Optimization studies of power plants and complexes. Novosibirsk: Academic publishing house "Geo", 2016.

[18] Kler A. M. (Ed.). Effective methods of circuit-parametric optimization of complex heat power plants: development and application. Novosibirsk: Academic publishing house "Geo", 2018.

[19] Kler A. M., Dekanova N. P., Tyurina E. A. Thermal power systems: optimization studies. Novosibirsk: Nauka, 2005.

[20] Mazumder S. Solution to a System of Linear Algebraic Equations. Numerical Methods for Partial Differential Equations 2016:103-167. https://doi.org/10.1016/B978-0-12-849894-1.00003-2

[21] Rozovsky A. Y., Lin G. I. Theoretical grounds of the methanol synthesis. Moscow: Khimiya, 1990.

[22] Kler A. M., Zharkov P. V., Epishkin N. O. An effective approach to optimizing the parameters of complex thermal power plants. Thermophysics and Aeromechanics 2016:23:289-96. https://doi.org/10.1134/S0869864316020165

[23] Luenberger D. G., Ye Yi. Linear and Nonlinear Programming. New York: Springer, 2008. https://doi.org/10.1007/978-0-387-74503-9

[24] Oil and Gas Journal "Info FEC". Analytics, documents, facts. 2020:1:33-56.

[25] Federal State Statistics Service. Statistics. [Online]. [Accessed 27.02.2020]. Available: https://www.gks.ru/folder/10705

[26] Regional Energy Commission of the Sakhalin Region. [Online]. [Accessed 27.02.2020]. Available: http://rec.admsakhalin.ru/tarify/ $\%$ D0 $\% 92 \%$ D0\%BD $\%$ D0\%B5\%D1\%88\%D0\%BD $\%$ D1\%8F\%D1\%8F

[27] Khabarovskenergosbyt, Far Eastern Energy Company. Tariffs. [Online]. [Accessed 27.02.2020]. Available: https://www.dvec.ru/khabsbyt/private_clients/tariffs/

[28] Dalenergosbyt, Far Eastern Energy Company. Tariffs. [Online]. [Accessed 27.02.2020]. Available: https://www.dvec.ru/dalsbyt/private_clients/tariffs/

[29] Methanol Institute. Methanol price and supply/demand [Online]. [Accessed 20.04.2020]. Available: https://www.methanol.org/methanol-price-supply-demand/ 